\title{
Historia del ecuavóley, análisis desde el paradigma educativo
}

Enviado: 8 de diciembre de 2021 / Aceptado: 30 de abril de 2021 / Publicado: 12 de julio de 2021

ALEX GALEANO-TERÁN

a.galeano@alumnosek.onmicrosoft.com

DOI 10.24310/IJNE4.1.2021.11168

\section{RESUMEN}

El presente trabajo de investigación evidencia un estudio inédito sobre la historia del deporte tradicional ecuatoriano "ecuavóley", su evolución deportiva analizada desde la perspectiva educativa. Se realizó un recorrido por su historia a partir de la visión antropológica social, teniendo como objetivo: determinar el origen e historia del deporte tradicional ecuatoriano ecuavóley, y cómo su evolución y práctica contribuyen con el currículo ecuatoriano de Educación Física. Para dar respuesta a este objetivo se realizó un estudio descriptivo, basado en la metodología cualitativa y sus cuatro fases, iniciando con la fase preparatoria y reflexiva, siguiendo con un trabajo de campo en el que se realizó entrevistas a profundidad, recolección de fotos, videos y artículos de prensa, concluyendo con un análisis histórico documental, periodo en el que se realizó la reducción y transformación de datos recogidos, finalizando con la elaboración y presentación del presente manuscrito. Como resultados se obtuvo que el origen e historia del deporte tradicional ecuatoriano "ecuavóley" se inició en las provincias de Imbabura, Loja y Pichincha a inicios del

\section{ABSTRACT}

History of ecuavolley, analysis from the educational paradigm

The present research work evidences an unpublished study on the history of the traditional Ecuadorian sport "ecuavolley", its sports evolution analyzed from the educational perspective. A journey through its history was made from the social anthropological vision, with the objective of: determining the origin and history of the traditional Ecuadorian sport of Ecuador, and how its evolution and practice contribute to the Ecuadorian Physical Education curriculum. To respond to this objective, a descriptive study was carried out, based on the qualitative methodology and its four phases, beginning with the preparatory and reflective phase, continuing with field work in which in-depth interviews, collection of photos, videos were carried out. and press articles, concluding with a documentary historical analysis, period in which the reduction and transformation of the collected data was carried out, ending with the preparation and presentation of this manuscript. As 
siglo XIX, aportando significativamente al currículo de Educación Física ecuatoriano, específicamente en los bloques juegos tradicionales y deportes con balón, ya que se aporta con bases para el desarrollo de clases teóricas y prácticas, contribuyendo así con el aprendizaje significativo, a su vez, mediante el análisis cualitativo del software Atlas.TI, se conoció que el término ecuavóley se comenzó a emplear a inicios de la década de 1950, siendo un aporte significativo para futuras investigaciones.

Palabras Clave: educación física, deportes de equipo, historia latinoamericana, ecuavóley. a result, it was obtained that the origin and history of the traditional Ecuadorian sport "ecuavolley" began in the provinces of Imbabura, Loja and Pichincha at the beginning of the 19th century, contributing significantly to the Ecuadorian Physical Education curriculum, specifically in the traditional games and sports blocks. with the ball, since it provides the basis for the development of theoretical and practical classes, thus contributing to meaningful learning, in turn, through the qualitative analysis of the Atlas.TI software, it was known that the term equuavolley began to be used at early 1950s, being a significant contribution to future research.

Keywords: physical education, team sports, latin american history, ecuavolley.

\section{INTRODUCCIÓN}

El ser humano evolucionó conjuntamente con los juegos y deportes que utilizan como implemento la pelota (Lavega, 2000). Según diversos estudios los juegos con pelota inician en el antiguo Egipto por los años 2635 a 2155 antes de Cristo, con la práctica del "aporraxis" actividad lúdica que tenía como característica principal, el golpeo de la pelota con la mano (Gorris, 1981).

Así mismo en Centroamérica se practicó un juego en el que se enfrentaban dos equipos de aproximadamente siete jugadores en un campo rectangular, supervisados por un juez, utilizando como implemento una pelota de hule que rebotaba en brazos o caderas, aproximadamente 2400 años antes de Cristo, llamado "chaaj" o también "pelota Maya" o "pelota mesoamericana” (Revilla, 2000).

En esta línea de tiempo resulta fundamental mencionar la práctica de juegos con pelota realizados por los griegos: llamado "harspanton" y por los egipcios "apórraxis", actividades deportivas desarrolladas en el siglo dos después de Cristo, eran muy similares en su forma de juego y reglas (Jiménez, 2019).

En este orden de palabras, los pueblos orientales en 960 después de Cristo también desarrollaron un deporte similar al voleibol, practicado masivamente principalmente en las gran- 
des ciudades de China, existía clubes y campeonatos con gran afluencia de espectadores, el juego era denominado como la "pelota China” (Mezcua, 2012).

Posteriormente, el continente americano durante la colonización estuvo muchos años ligado a España, esto permitió intercambiar innumerables formas de vida, cultura y tradiciones, a esto se le debe sumar el mestizaje del que fueron parte los españoles, por parte de pueblos con asentamientos reales y especialmente prolongados en el tiempo (romanos, cartagineses, visigodos, iberos, celtas, pueblos bárbaros de origen germano, pueblos de comerciantes de todas las márgenes del mar Mediterráneo, árabes, judíos, etc.). Esta cultura se ha conservado y transmitido de generación en generación, fundamentalmente de forma oral y en el ámbito deportivo Jiménez (2019).

Por su parte la colonización española al continente americano aportó con cultura y tradiciones a muchos países sudamericanos entre ellos Ecuador, ya que el estado español en su conjunto se puede definir como un país rico en juegos y deportes tradicionales, debido a características territoriales y su ubicación estratégica entre los continentes, europeo y africano.

Producto de esta riqueza cultural y deportiva, años más tarde nace en Ecuador, un deporte "bautizado" como "ecuavóley". Actividad practicada diariamente por miles de ecuatorianos, dentro y fuera del Ecuador, incluso superando en muchas provincias a la afición por el fútbol (Galeano-Terán y Chuquín, 2020). Debido a esta popularidad actualmente está considerado como un "deporte tradicional", dentro del currículo ecuatoriano de Educación Física, practicado en el bloque curricular 4, que lleva por nombre: "prácticas deportivas".

El currículo ecuatoriano de Educación Física tiene la característica de ser abierto y flexible, por ello permite al profesorado incluir en las planificaciones de área las actividades más practicadas por la población ecuatoriana así lo manifiesta el Acuerdo ministerial (0041-14/2016). Según Galeano-Terán (2018), los docentes de las instituciones educativas planifican, incluyen y ejecutan sus actividades tomando en cuenta los deportes que tienen mayor afinidad alumnos y alumnas, por ello, en la mayoría de instituciones educativas se incluye al ecuavóley en sus planificaciones.

En este sentido Martínez (2018) afirma que, actualmente en Ecuador los deportes que más llaman la atención a los y los estudiantes son el fútbol y ecuavóley, siendo estos los más practicados por la población ecuatoriana. De acuerdo con (Galeano-Terán, 2020a):

“Actualmente (...) el ecuavóley es uno de los deportes más practicados, superando el fútbol, ya que diariamente centenares de fanáticos y jugadores que practican el ecuavóley se dan cita en los principales polideportivos" (p.81). 
Debido a la popularidad mencionada anteriormente, el ecuavóley "Actualmente es practicado en Ecuador, Colombia, Perú, Chile, Estados Unidos, Suiza, Italia, Francia, Inglaterra, España, Bélgica y Suecia”, (p.323), sustenta (Galeano-Terán, 2020b).

Por ello la importancia de este trabajo que permitirá conocer la evolución del ecuavóley, de dónde nace, y cómo se convierte en uno de los deportes más practicados por la población ecuatoriana, de esta manera aportando con la comunidad educativa ecuatoriana. Resulta oportuno mencionar el limitado número de artículos científicos o investigaciones serias que permitan determinar a ciencia cierta el origen del ecuavóley, qué provincia o provincias ecuatorianas iniciaron con su práctica, qué deportes extranjeros influenciaron en su evolución deportiva y como esta práctica deportiva favorece en la formación integral.

En este orden de palabras, es clave mencionar que en cada rincón del territorio ecuatoriano que se visite se encuentra una cancha de ecuavóley (Figura 1), a sus alrededores negocios de comida o bares, y cientos de personas de todas las edades dándose cita a jugar u observar un partido.

Figura 1. Complejo deportivo ecuavóley, Otavalo, Ecuador. Fuente: elaboración propia (2015).

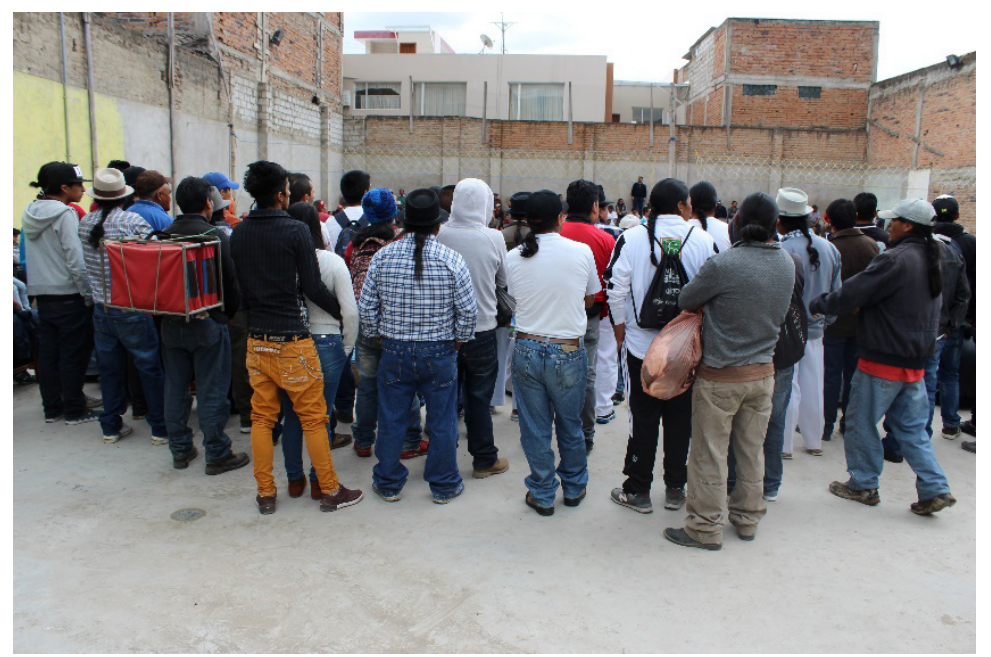

\subsection{Historia y descripción del juego}

En este apartado se iniciará con un análisis descriptivo general, sobre las características de la cancha de juego, implemento, jugadores, jugadoras y modalidades, posteriormente se realizará un análisis bibliográfico histórico sobre el origen y evolución de algunos juegos con pelota, permitiendo perfilar al ecuavóley desde el enfoque educativo con el objetivo de conocer sus raíces y evolución, en este sentido, menciona Sainz (1992), que los deportes son manifestaciones que acompañan al hombre desde su aparición sobre la tierra, este, en su evolución y civi- 
lización, constantemente los desarrolló, pero han estado orientadas hacia diversos objetivos formativos y recreativos.

El ecuavóley es practicado dentro y fuera de las instituciones educativas, se utiliza como principal implemento un balón de fútbol número 5, una red y cualquier superficie plana de 9 metros por 9. Tiene como objetivo hacer caer el implemento superando una "red" o net, ubicada como mínimo a 280 y máximo $285 \mathrm{~cm}$, haciendo que el balón golpee dentro del rectángulo de 9 metros por 18 metros, en dónde están ubicados tres rivales.

La cancha de ecuavóley se encuentra dividida en dos cuadrados iguales de nueve metros por una línea infinita en la mitad, la particularidad de este deporte es que se juega a quince puntos y se juega con cambios, es decir, que un equipo debe mantener el saque durante dos veces seguidas para que se otorgue un punto. Se juega a 15 o 12 puntos en la sierra y a 12 o 10 puntos en la costa, Galápagos y Amazonía.

El número de jugadores o jugadores, son tres en cada equipo, sin cambios en partidos regulares "apostados" y con dos o tres cambios en campeonatos oficiales. Sobre las apuestas se puede mencionar que esta particularidad se observó también en algunos deportes y espectáculos tradicionales de la antigua China (Torrebadella-Flix, 2019).

Como se mencionó anteriormente, la cancha de ecuavóley tiene una característica rectangular, ubicada en espacios planos. Debido a estas particularidades se hace evidente que el ecuavóley también tiene influencia de la pelota maya, juego mexicano practicado en un campo rectangular y plano (Burgués, 2000), concordando con Cifuentes y Ramírez (2019):

\footnotetext{
"En el chaaj, el objetivo es pasar la pelota por un anillo ubicado a una altura de unos tres metros y en el centro de un tablero de madera. La estructura mide aproximadamente entre 6 y 10 metros de largo por 4 de alto, y presenta una inclinación haciendo ángulo agudo de entre 70 a 60 grados con el piso" (p.121).
}

Las características de la cancha hacen evidente la influencia del "chaaj "o pelota maya, en la práctica del ecuavóley. Particularmente en Ecuador, según registros videográficos, archivos, documentos y fotos que se explicarán y analizarán más adelante, el ecuavóley tiene sus inicios a comienzos de 1900, iniciando su práctica en Imbabura y Loja, relacionándolo con el voleibol, afirmaciones empíricas locales que aún no han sido confirmadas, esto debido a la escasez de investigaciones, respecto al origen del voleibol, las investigaciones también son escazas (Torrebadela-Flix, 2019). 
En este sentido, a causa del reducido número de trabajos sobre la historia del voleibol, podría conllevar a tergiversar el origen del ecuavóley, más aún, tomando en cuenta que existían otros deportes con pelota en China, en el año 960 Antes de Cristo, el autor López (2012) explica que: en la dinastía Song, el juego alcanzó tal popularidad que en las grandes ciudades se organizaron clubes en los que sus miembros tenían que pagar cuotas de suscripción por jugar, había dos formas de juego y era un deporte muy similar al voleibol.

En el siglo XI, en España se jugaba un juego denominado "la pelota", era el deporte preferido para solemnizar las celebraciones religiosas, tendía a saltar esta limitación espacial, en lugares en los que una fiesta era menos fiesta sin un desafío frente al frontón o frente a la pared que hacía sus veces, entre jugadores locales y pelotaris que acudían de otros pueblos, tierras o provincias no siempre limítrofes.

Esto dependía de la resonancia que alcanzara la festividad o de la importancia del pueblo que la celebraba, (Jiménez, 2019), el ecuavóley posee una característica similar, actualmente se lo practica en la celebración de fiestas religiosas y de fundación, a lo largo y ancho del territorio ecuatoriano y fuera de él, acudiendo equipos invitados de otras parroquias, cantones o provincias, e inclusive países, atractivo que llama la atención de cientos y muchas veces miles de personas que acuden a presenciar el espectáculo deportivo, inclusive pagando entradas. Otro atractivo del ecuavóley son las apuestas, que pueden ir desde centavos de dólar hasta miles de dólares.

Estas características culturales han sido heredadas desde hace miles de años, ya que antiguamente el elemento rey de las festividades eran los juegos con pelota, estos juegos aportaban gran número de posibilidades para desarrollar habilidades físicas básicas como lanzar, recibir, pasar, golpear, rodar, botar, entre otras, por ello los juegos de pelota ya eran conocidos en el antiguo Egipto, así como en Grecia, bajo la denominación de aporraxis. Este juego consistía en botar la pelota con la mano. Los griegos jugaban a la anacrousia, que era el juego del frontón, otras evidencias de las prácticas de estos juegos romanos han quedado reflejadas en las iconografías de porcelanas con estelas funerarias de atletas, como es el caso de la Estela funeraria de un atleta de la primera mitad del siglo iv a C., encontrada en El Pireo, Atenas (Museo Arqueológico Nacional de Atenas) (Gorris, 1981).

Estas particularidades, demuestran que el ecuavóley tiene influencias culturales, sociales y deportivas de juegos con pelota practicados en la antigüedad, pese a la limitada información sobre el origen del ecuavóley y su aporte a la educación ecuatoriana, no le ha restado impor- 
tancia cultural, educativa y deportiva, ya que el ecuavóley lleva en sus entrañas la esencia del pueblo ecuatoriano. En este sentido, resulta oportuno mencionar a Diem (1966), quién afirma:

“Cada época crea su deporte, y la esencia de cada pueblo se refleja en éstos”, (p.6).

La afición por el ecuavóley es evidenciada mediante su práctica masiva, que va aumentando a través de los años, incluso trascendiendo las fronteras patrias, llegando a ser exhibido en olimpiadas juveniles Lausanne 2020 (Figura 2), proyecto presentado desde el año 2018 para su aprobación, por la Asociación de ecuatorianos en Lausanne Suiza, evento al que se dio cita por primera vez en la historia un equipo profesional ecuatoriano, movilizado únicamente para esta presentación.

Figura 2. Exhibición en olimpiadas juveniles de invierno en la ciudad Olímpica, Lausanne, Suiza. Fuente: elaboración propia (2020).

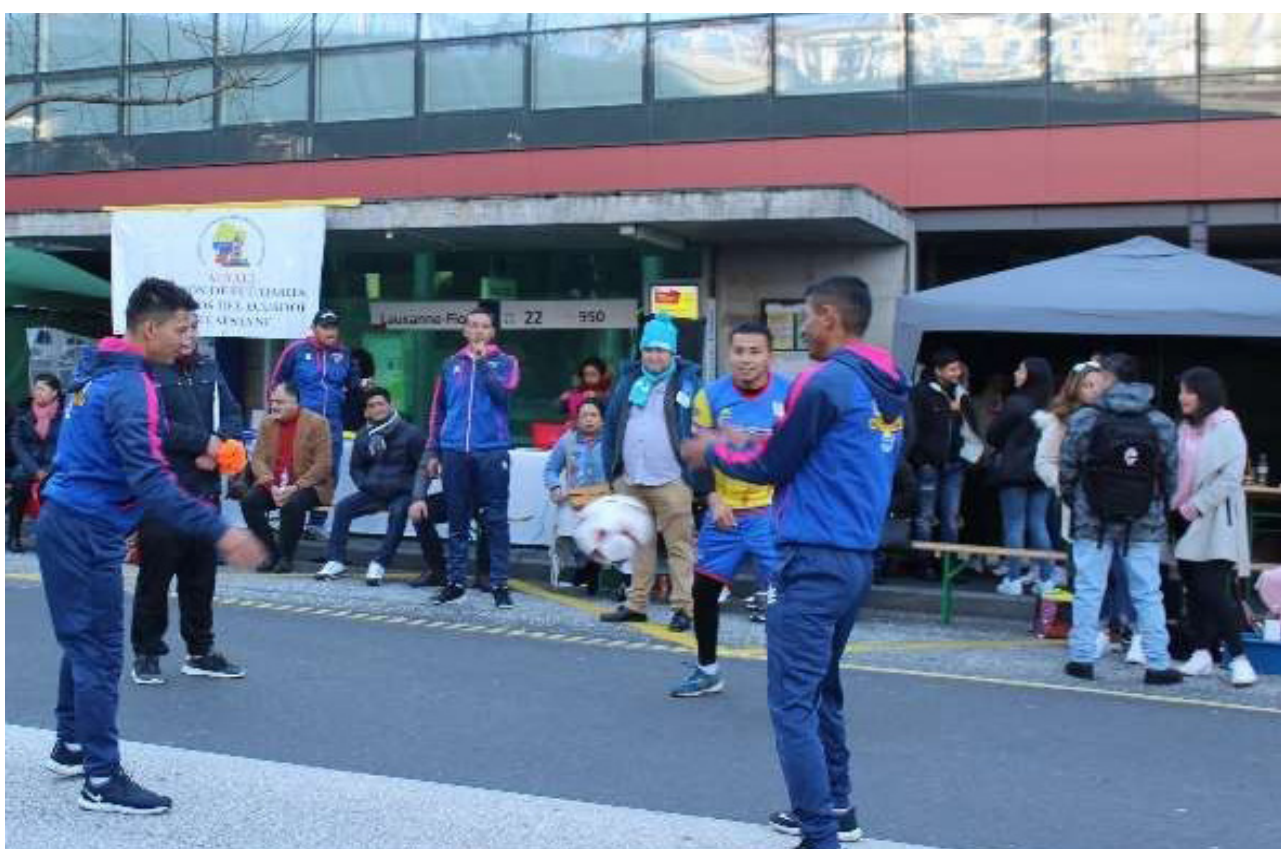

\subsection{Variantes}

Como todo deporte que utiliza un implemento, el ecuavóley también ha sufrido ajustes, de acuerdo a los requerimientos de la sociedad y de las personas que lo practican. Bringas (2002) señala que hay que respetar el equilibrio entre la tradición y la renovación. La reforma de este deporte surge cuando se modifica el número de jugadores a uno o dos a cada lado, permitiendo realizar el mismo número de golpes, muchas veces incluyendo el pie o cabeza, además de la 
forma de sacar la pelota (Figura 3). A pesar de estos pequeños cambios, mantiene su esencia y características como es la altura de la red a 280-285 cm y el implemento un balón de fútbol, y la forma y materiales de la red (Galeano-Terán y Chuquín, 2020).

Figura 3. Partido ecuavóley dos a dos, sacando con el pie, Cotacachi, Ecuador. Fuente: elaboración propia (2015).

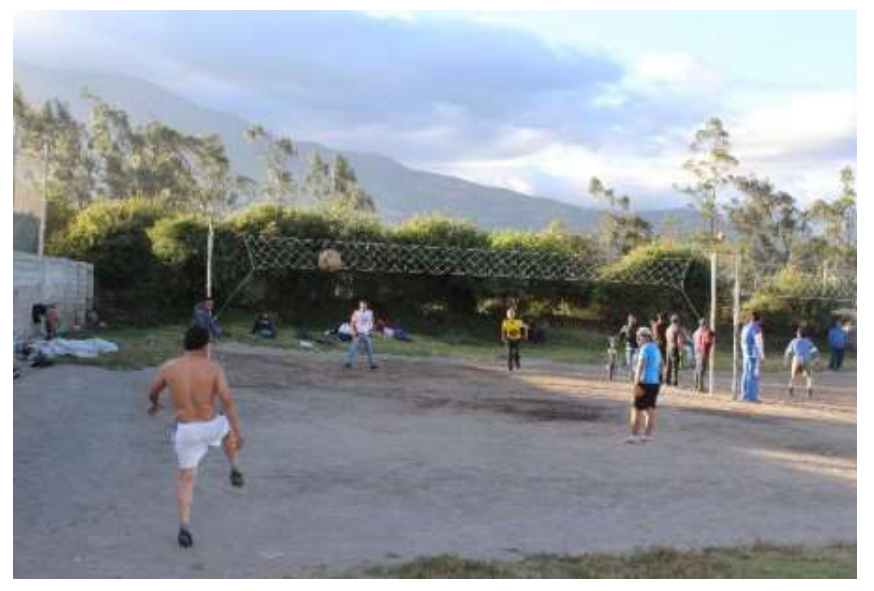

Este tipo de variantes pueden ser trabajadas de una manera lúdica y recreativa en las instituciones educativas, brindando nuevas formas de enseñanza en Educación Física, potenciando la formación integral de alumnos y alumnas, dándole un sentido educativo al ecuavóley, como ha ocurrido con la mayoría de deportes desde los inicios de la humanidad, que fueron concebidos como una práctica para la supervivencia hasta que comenzaron a contener contenido educativo, transformando el concepto y otorgándole variedad de interpretaciones, que han influenciado a la cultura y educación de hoy (Sainz, 1992; Blanco, 2016).

\section{MATERIAL Y MÉTODO}

Con la finalidad de cumplir con los objetivos de investigación planteados en este artículo: determinar el origen e historia del deporte tradicional ecuatoriano ecuavóley; establecer una teoría fundamentada sobre los inicios del ecuavóley, con la finalidad de aportar al currículo de Educación Física ecuatoriano; analizar el aporte educativo a través de la historia; determinar la época y provincias del país en la que se inició la práctica de este deporte; conocer el período en que comenzó a usarse el término "ecuavóley".

Se realizó un estudio descriptivo, debido al interés por encontrar información verídica emitida por los actores entrevistados en condiciones naturales, es decir en la realidad de estudio 
(Salinero, 2004), este método es una herramienta de la investigación cualitativa, ya que contribuyen con estrategias de investigación transversales aplicables a estudios relacionados con historia y educación (Paz, 2003), concepto que se adapta a las características del presente estudio, ya que utilizó la interpretación empírica como estrategia para operacionalizar las variables.

La investigación cualitativa posee como característica principal la diversidad metodológica, en donde cada enfoque o corriente mantiene sus propias formas de ejecutar la investigación, dando la apertura al investigador para aplicar estrategias de acuerdo a su experiencia, tomando en cuenta la particularidad etnográfica de este trabajo inédito, no se puede hablar de un proceso rígido de investigación, sino del desarrollo de actuaciones ordenadas, que permitieron acercarse a la comprensión de lo estudiado.

"Toda la investigación cualitativa, incluyendo la evaluación cualitativa, es y debe ser guiada por un proceso continuo de decisiones y elecciones del investigador", (Pitman y Maxwell, 1992, p.753).

Por ello se empleó una metodología empírica-analítica, enmarcada en cuatro fases: preparatoria, trabajo de campo, fase analítica e informativa, como se mencionó anteriormente, este proceso tomó en cuenta el punto de vista del investigador, ya que, pese a la variedad metodológica de la investigación cualitativa, posee algo común entre los enfoques, que la toma de decisiones será sometida y procesada por el investigador (Pérez Juste, 1985; Schwandt, Denzin y Lincoln, 1994; Atkinson, Coffey y Delamont, 1999; Gil, Rodríguez, y García, 1999; Pole y Lampard, 2002).

Al mismo tiempo, se incluyó un análisis mediante la teoría social para extraer de ella aquellos elementos conceptuales que pueden proporcionar una mejor comprensión del papel del deporte como vía de transmisión de valores y conocimiento, como mecanismo de integración social o como dispositivo de producción de nuevas formas sociales de aprendizaje (Sánchez, 2020).

De esta manera también se utilizaron algunas estrategias de investigación creadas para dar respuesta a estudios de los deportes ancestrales que buscan reconstruir la génesis de aquellos, y debido a la antigüedad de los mismos, no quedan pioneros de su práctica, únicamente testigos con vida que podrán dar fe de los inicios deportivos, siendo clave incluir la exploración de hemerotecas, fotos, videos, archivos públicos y privados, de descendientes de los primeros jugadores de ecuavóley, además de entrevistas, (Esparza, 2019). 
Además, se empleó el trabajo de exploración y búsqueda de archivos con la finalidad de localizar información verás a partir de un estudio documental e información directa, (De Gialdino, 2006; Deslauriers, 2004). Situándolo desde un enfoque descriptivo y teniendo como base estudios de campo y análisis documental, fundamentado con el método científico, (Pardo, Ruiz y San Martín, 2015).

Es común que, en una investigación cualitativa, se utilice más de un instrumento para recolectar la información, entrevistas, observación etnográfica, participante o pasiva, historia de vida análisis de videos y fotos.

Cuando esto ocurre es necesario integrar la información de los instrumentos mediante la formulación de conclusiones, entonces es posible afirmar que se cuenta con un corpus coherente y organizado que reflejará los resultados reales de la investigación (Cabrera, 2005). Se aplicó la técnica de la observación; basada en la información documental, además del análisis de documentos, videos y la entrevista en profundidad (Duverger, 1996).

Otro de los instrumentos utilizados fue la observación directa extensiva e intensiva, y una entrevista no estructurada con preguntas abiertas, ayudando en la toma de decisiones sobre situaciones centrales, perfilando la investigación a escenarios centrales de recolección de documentos (Aróstegui, 1995). En la observación documental se incluyeron algunos archivos de prensa, redes sociales y textos bibliográficos, facilitando al método hermenéutico la interpretación de datos sobre el origen del ecuavóley.

\section{RESULTADOS}

La muestra de sujetos entrevistados fue elegida adecuada y responsablemente, ya que en metodología cualitativa el investigador debe tener la sagacidad y experticia para escoger personajes claves que brinden información verídica, en este caso fueron ex jugadores y aficionados que conocían la historia del ecuavóley, quienes a su vez aportaron con testimonios, fotos, videos, recortes de periódicos y libros que permitieron llegar a conocer el inicio de esta práctica deportiva en Ecuador, tomando en cuenta que este grupo de personas representa científicamente a la población de estudio (Bisquerra y Alzina, 2016).

Finalmente se efectuó el análisis e interpretación de datos y referencias, para posteriormente explicar los resultados de una manera comprometida utilizando la hermenéutica, basándose en subcategorías que permitieron obtener conclusiones específicas alejándose de subjetividades explícitas. 
La historia aporta a la educación con un campo disciplinar que permite replantear repetidamente sus contenidos y sus finalidades, respondiendo a su vez a los contextos específicos e intereses académicos (Viñao Frago, 2016). El aporte de la historia a la educación se convierte en una posibilidad de retornar actividades herederas con perspectivas actuales y nuevas formas de prácticas pedagógicas (Pulido-Cortés, 2017).

Particularmente en el currículo ecuatoriano de Educación Física se menciona que es un deber de la materia contribuir al perfil de salida del Bachiller ecuatoriano, favoreciendo a la formación integral de cada estudiante que transite desde la Educación General Básica hasta el Bachillerato y tomando en cuenta que deberá ser impartida de manera teórica y práctica, contribuyendo con saberes que sirvan para la vida y no únicamente para el momento.

Se inició con entrevistas realizadas a aficionados claves y ex jugadores, posteriormente se realizó el análisis exhaustivo de fotografías y videos pertenecientes a familiares y amigos de personas que iniciaron con la práctica del ecuavóley, incluyendo un análisis bibliográfico en bibliotecas y museos.

\section{Testimonio 1:}

"Nací en 1941 el 22 de junio. cuándo quizá tenía una edad entre 9 o 10 años observaba a mis mayores grandes deportistas que en esa época ya jugaban ecuavóley (...) paraban dos palitos y una soga (...) en un lugar plano ubicado frente a la hacienda antigua de Yacucalle, por ahí templaban la soguita comenzaban a jugar grandes partidos (...) más abajo, donde es actualmente la Av. Teodoro Gómez y Atahualpa era un potrero, en ese tiempo no había calle, era solo un callejón que salía hasta Caranqui, en ese llano vacío se jugaba ecuavóley o fútbol, ahí nace el club los Imbayas. Yo era muchacho, pero mis mayores ya jugaban, desde ahí recuerdo nace la práctica de este deporte en el barrio, inclusive los vecinos mestizos jugaban, pues se familiarizaron con nosotros, los indígenas jugaban grandes encuentros de ecuavóley, recuerdo mucho eso, pues la verdad de ahí aprendí a jugar, ya había buenos jugadores, nos formamos jugando en potreros”.

"Con el tiempo, al observar el incremento de las personas que jugaban, construyeron una cancha muy bonita donde alquilaban los servicios (...) que yo recuerde de esta forma dejaron de jugar en la calle, créanme que en esas canchas se comenzó a jugar todos los días”.

\section{Testimonio 2:}

"Nací en medio de los amantes del ecuavóley, como campesino lo practiqué desde los primeros años de la escuela como actividad recreativa, fuimos perfeccionando las habilidades de esta dis- 
ciplina deportiva muy nuestra, muy ibarreña, muy ecuatoriana, más tarde salimos ya a buscar escenarios donde podíamos participar, cuando tenía 15 años ahora tengo 55, encontramos un escenario de mucha afluencia que estaba muy cerca del mercado amazonas en la Av. Pérez guerrero, este escenario era administrado por la familia Vaca donde acudían decenas y centenarios de aficionados se llevaban grandes partidos intercambios deportivos con selecciones y equipos de otras provincias, después de un tiempo (...) recuerdo se instalan canchas en los terrenos del ferrocarril ahí habían tres canchas divididas de acuerdo al nivel de cada categoría, imaginariamente los más malos, los medianamente buenos y los buenos, esto a su vez crea una serie de actividades paralelas, si bien es cierto había un administrador quien ofrecía la comida rápida o refrescos, salas de juego simultaneas también alrededor del cerramiento que era de mallas habían otras personas que ofrecían productos a las personas que se daban cita todos los días de lunes a domingo permanecían en esos espacios”.

\section{Testimonio 3:}

"En lo que se refiere al ecuavóley como deporte tradicional ecuatoriano, debo manifestar que desde mi infancia, donde naci en Bellavista, perteneciente a la parroquia de San Antonio de Ibarra, indudablemente era el lugar donde todos los vecinos del barrio se reunían, en especial fines de semana era donde existía una cancha de ecuavóley, obviamente era el momento de recreación donde formando equipos parejos de acuerdo a las condiciones y habilidades se jugaba en las tardes y obviamente ese era el lugar donde sin límite de edad participaban los miembros de la comunidad, disfrutaban, discutían, alegaban, pero siempre estaba el jolgorio dentro de la cancha de ecuavóley" Por mi parte jugué desde la edad de 12 años con los compañeros y amigos discutíamos a veces como es costumbre al jugar ecuavóley pero al final no había displicencias (...) pasado las cuatro de la tarde salían a jugar uno o dos partidos de ecuavóley para luego retirarse a su casa no olvidemos que no había iluminación y ese era el lugar de sano esparcimiento también visite el sector de Chuga jugaban mucho ecuavóley en la época más o menos de 1964”.

"Después ingresé a la universidad en la ciudad de Quito, alli pude observar un campeonato en el Coliseo fulio Cesar Hidalgo, donde el ecuavóley evolucionó, la primera vez que pude observar un partido de ganchadores. Obviamente el tradicional ecuavóley era el "muñequeo" modalidad ponedores o colocadores indudablemente atraía muchos aficionados y también se veía las cualidades físicas y el gusto por practicar este deporte, en la actualidad siguen practicando el ecuavóley en sus diferentes modalidades, debo manifestar recuerdo que los tradicionales rivales eran aduana policía y ejército" 


\section{Testimonio 4:}

"Desde tiempos de antaño conocemos al ecuavóley como una actividad de recreación, en un inicio lo practicaban comunidades indígenas en las horas libres al culminar sus largas jornadas de trabajo en la hacienda, ellos buscaban un espacio de recreación y distracción que les permita descansar y disipar sus arduas horas de trabajo, esto puedo comentar en el cantón Cotacachi de donde provengo. Es así como nace esta práctica deportiva según contaban mis mayores ubicaban dos chawarkeros (postes hechos del tallo de los pencos) en algún terreno plano, y ponían entre ellos una vena de zambo así comenzaron a jugar pasando una pelota de un lado al otro desconocemos el tipo de material de este implemento que utilizaban en un inicio, posteriormente se va masificando este deporte y comenzaron a practicarlo en plazas y calles del cantón no se sabe en qué época exacta comenzó el uso de la red, luego comenzaron a jugarlo 3 a 3 en la actualidad es uno de los deportes más practicados seguramente luego se implementó reglas del voleibol hasta evolucionar al juego que conocemos".

\section{Testimonio 5:}

"El ecuavóley es muy importante en mi vida, mientras tenga fuerzas nunca dejaré de practicarlo, el ecuavóley lo practico desde que era muy pequeño luego formé parte de la selección del colegio, también comenzaron a practicar voleibol, pero no nos llamó la atención jugar seis a seis, es por ello que inclusive a nivel nacional ha tomado más fuerza el ecuavóley este deporte eminentemente ecuatoriano como su nombre lo indica. "Recuerdo que habían campeonatos inter barriales ò inter clubes en Atuntaqui de donde soy originario hace más o menos 40 años, actualmente seguimos impulsando este deporte de manera recreativa realizando campeonatos en varias canchas de la provincia, entre ellas Imbaya, lo realizamos en el mes de diciembre iniciando con la inauguración los equipos conformados por lo menos por cuatro jugadores, todos correctamente uniformados y con madrina, para luego culminarlo con la premiación se entrega pequeños incentivos cómo medallas y trofeos, pero sobre todo prevalece la dignidad deportiva inmediatamente después un programa social y lectura del testamento entre amigos y finalmente la quema del año viejo, de igual manera realizan posteriormente el campeonato en la cancha de la ciudadela municipal ubicada en Ibarra eventos que se están institucionalizando y cada vez hay más equipos participantes, pues el ecuavóley es un deporte maravilloso que convoca a multitudes de personas y es creado en Ecuador por ello las autoridades deben fortalecerlo además el deporte nos mantiene con buena salud y alejados de los vicios de esta forma incentivamos a niños y jóvenes a la práctica deportiva”.

Como se puede observar, en las entrevistas a profundidad la práctica del ecuavóley en la provincia de Imbabura tiene sus inicios frente a la hacienda "Yacucalle", término mezcla de 
kichwa y español significa calle de agua, lugar en el que construyeron una cancha de ecuavóley con una red improvisada, en la cual jugaban indígenas y mestizos diariamente al terminar la jornada laboral, formándose un ambiente de amistad, unión y aprendizaje de costumbres y técnicas de juego.

Implícitamente el ecuavóley lleva en su esencia la unión de los “vecinos”, que diariamente se daban cita a observar o jugar, a la vez que se desarrollaban espacios de unión, sana convivencia intercambio de experiencias, espacios que daban también lugar a la preparación y venta de gastronomía ecuatoriana.

Con la finalidad de conocer la década en que surgió la palabra "ecuavolley" las entrevistas a profundidad fueron analizadas en el programa ATLAS.ti. A continuación, se puede observar el resultado de dicho estudio.

Figura 4. Nube de palabras entrevistas. Fuente: Software, ATLAS.ti. 2020.

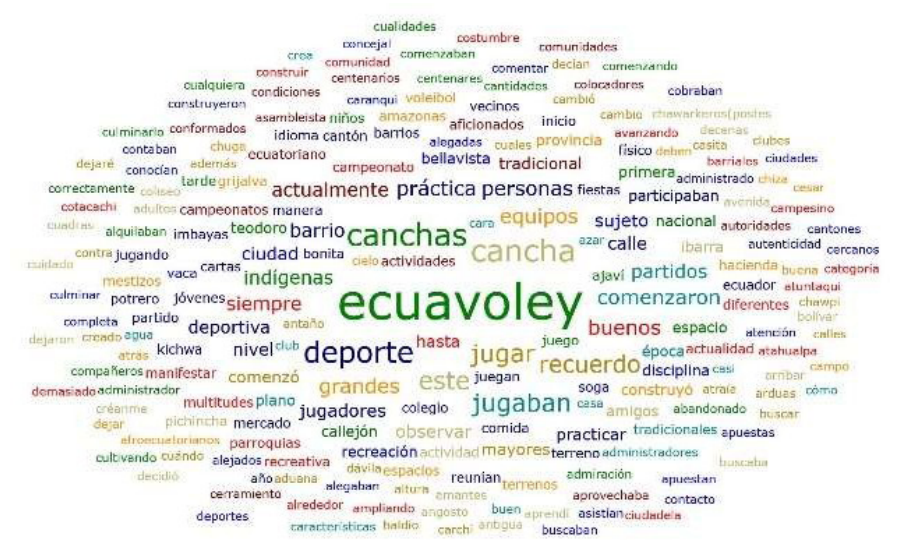

Mediante este análisis estadístico del programa cualitativo ATLAS.ti se puede observar claramente que el término "ecuavóley" era conocido desde los inicios de la práctica de este deporte, evidenciándose que en 1950 ya llevaba este nombre, contrastando con la teoría que era llamado "vóley criollo", hasta antes de la década de los setenta, resultados que coinciden con el criterio de Galeano (2003). La investigación cualitativa permite analizar datos descriptivos, así como el comportamiento observable de la persona, permitiendo conocer la realidad social, así como el comportamiento observable de la persona y su verdadera historia.

En este sentido, se puede afirmar que en la provincia de Imbabura el ecuavóley era practicado por indígenas y mestizos, una vez culminadas las actividades diarias, la primera cancha de esta provincia estuvo ubicada frente a la hacienda "Yacucalle" a inicios de 1900, cuyo objetivo implícito era la recreación de niños, jóvenes y adultos, el impacto cultural del ecuavóley se ve 
reflejado en el número de personas que practicaban y practican este deporte a nivel nacional. Es de esta manera, como se analiza e interpretan los grandes acontecimientos de la sociedad; desarrollando conceptos que permiten conocer e interpretar el pasado, colaborar con el presente y pronosticar el futuro (Strauss y Corbin,2016).

\subsection{Análisis documental y de información}

Con el fin de concretar una teoría fundamentada sobre la historia del ecuavóley, y aportar con la educación ecuatoriana, se utilizó el análisis documental como una forma de investigación técnica, en dónde actúan un grupo de operaciones intelectuales que buscan describir y representar la información sistemática para facilitar su recuperación.

Comprende el procesamiento analítico que, a su vez, incluye descripciones generales de la fuente, la clasificación, confección de reseñas, brindando valor de la información para su interpretación, estos procesos hacen necesario ahondar en el análisis documental como proceso mediador en búsqueda de un objetivo de investigación cualitativa, pues en el contexto actual, el análisis de información adquiere una relevancia extraordinaria, porque desbroza el camino, "intoxicado" por la creciente circulación de datos e información innecesaria. Su realización exitosa y eficiente genera una mejor utilización del conocimiento disponible en aras de acelerar el proceso de su implementación en investigación para la obtención de resultados (Peña Vera y Pirela Morillo 2007; Dulzaides Iglesias y Molina Gómez 2004).

Específicamente el análisis documental de fotografías juega un importante papel en la visualización de las actividades políticas, sociales culturales, religiosas, académicas o deportivas, del hombre que, convirtiéndola en un verdadero documento social, en el caso de esta investigación se analizarán fotografías con referente identificable sin texto aclaratorio.

El análisis de contenido fotográfico permitió denotar descriptivamente las imágenes jerarquizando seres humanos jugando ecuavóley, aplicando el paradigma de Lasswell ¿quién?, ¿qué?, ¿dónde?, ¿cuándo?, ¿cómo? El análisis documental conforma un ámbito de considerable valor en relación con la fotografía, como instrumento metodológico que no sólo tiene una utilidad práctica, sino que también contribuye al conocimiento y la valoración social y académica de estos materiales. (Vilches, 1993; Del Valle Gastaminza, 1999; Sánchez, 2006; Marzal, 2007; Torregrosa, 2010).

En este apartado se analizará fotos, videos y artículos de prensa permitiéndonos dar respuesta a los objetivos planteados, comenzando con la imagen más antigua encontrada hasta el momento: 
Figura 5. Indígenas junto al dueño de hacienda, Imbabura, Ecuador, inicios de 1900. Fuente: elaboración propia (2020).

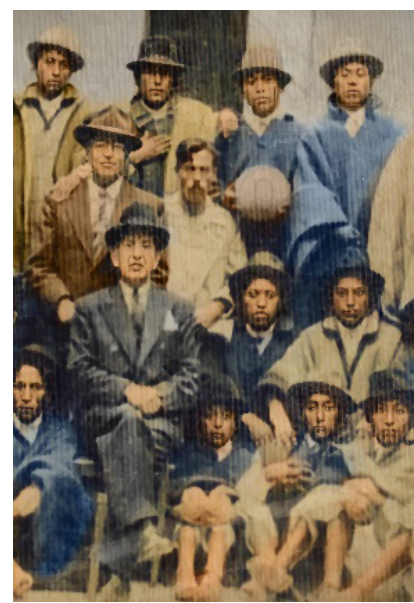

Iniciando con el análisis en la búsqueda del origen del ecuavóley, se puede observar en la figura 5, una foto inédita colorizada digitalmente en la que se puede observar indígenas Imbabureños, posiblemente Otavalos junto a los dueños de hacienda en las manos una pelota de ecuavóley, marcando los inicios de esta práctica deportiva.

A continuación, se observa el calentamiento previo a una exhibición, no se puede determinar con precisión si es de ecuavóley o voleibol, este evento fue realizado al sur del Ecuador:

Figura 6. Exhibición, Loja, Ecuador 1930. Fuente: Archivo histórico Banco Central del Ecuador .

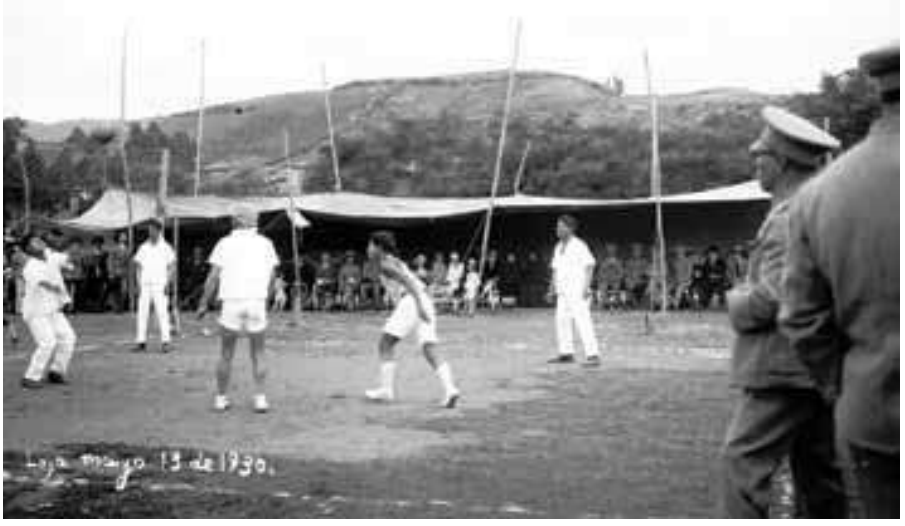

En la Figura 6 se puede observar una banda marcial, ubicada al contorno de una cancha de ecuavóley, personas sentadas bajo viseras improvisadas, mientras 5 personas juegan en una cancha rectangular evidenciando una red de ecuavóley en la mitad. En la parte inferior izquierda existen escritos que dicen: Loja, mayo 13 de 1930. 
Figura 7. Banda de guerra en cancha de ecuavóley, Loja, Ecuador 1934. Fuente: Archivo histórico Banco Central del Ecuador

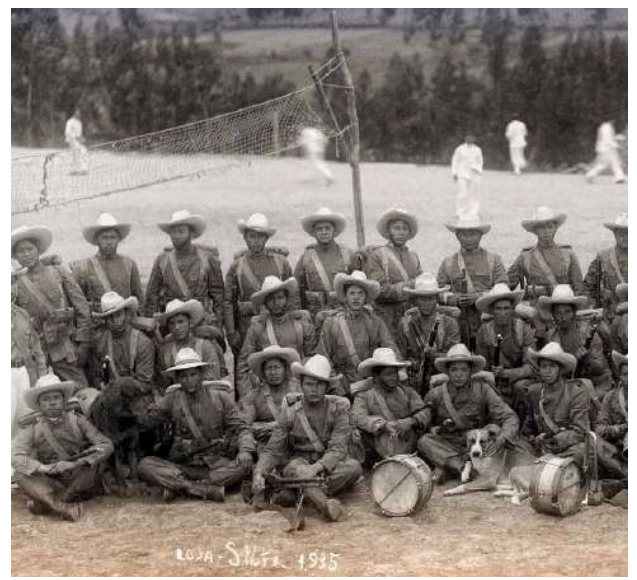

Posteriormente, en la Figura 7 se observa una banda de "pueblo" (1935) con un perro, en la parte posterior se observa una improvisada "red" de ecuavóley tejida probablemente con "cabuya" fibras de las hojas de un "espino", tensada sobre la rama de un arbusto, y al fondo niños con trajes blancos jugando.

Figura 8. Loja, Ecuador 1935. Fuente: archivo histórico Banco Central del Ecuador

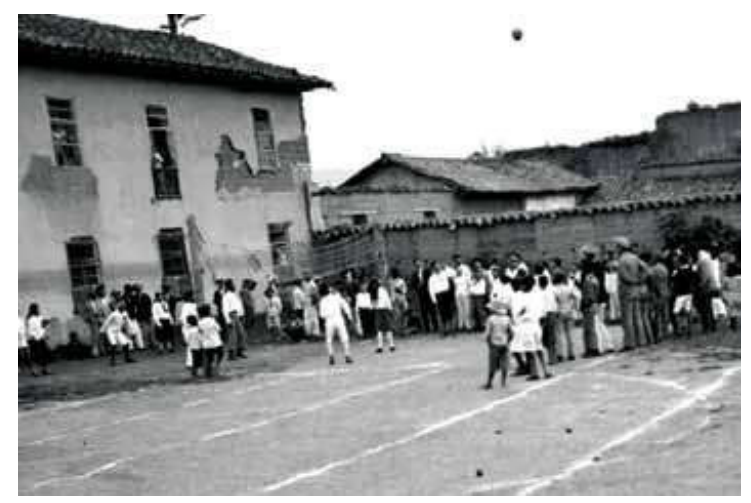

En la Figura 8, se puede apreciar un grupo de personas observando un encuentro deportivo, en el cual están jugando hombres y mujeres, se distingue nuevamente 5 personas a cada lado de la cancha, situación por la cual no se puede afirmar si es partido de ecuavóley o voleibol, pero destaca un gran número de personas observando, desde aquella época se daban cita a observar el juego.

En la Figura 9 se aprecia a 5 personas a cada lado jugando con una pelota de fútbol, se desconoce la fecha exacta, de la misma manera que imágenes anteriores se evidencia un gran número de personas observando, y debido al número de jugadores no se puede asegurar que sea voleibol o ecuavóley. 
Figura 9. Exhibición voleibol, Loja, Ecuador, s/f. Fuente: archivo histórico Banco Central del Ecuador.

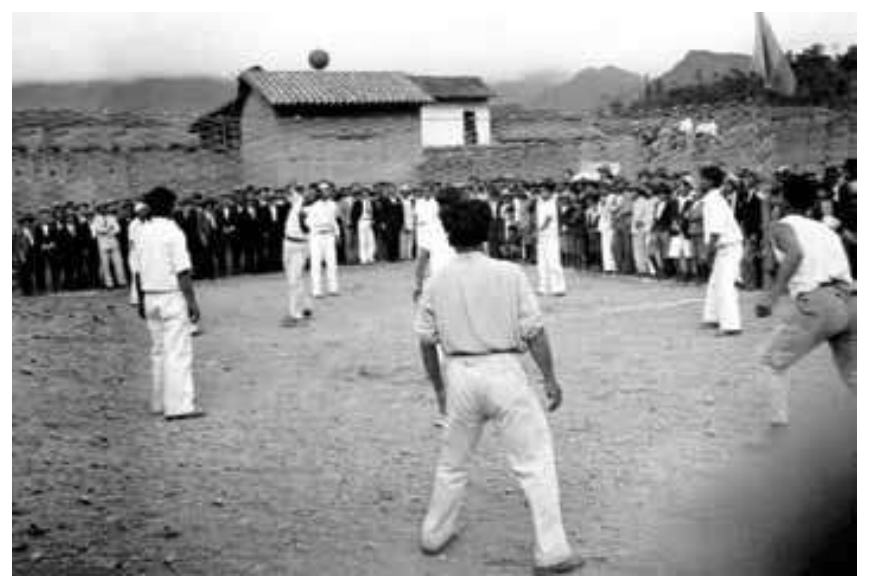

La imagen que se observa a continuación, fue tomada en Quito, en 1950 observándose la fina de un campeonato barrial de ecuavóley, se puede observar la presencia de una gran cantidad de espectadores, siendo la evidencia del primer campeonato de ecuavóley registrado.

Figura 10. Campeonato de ecuavóley, Quito, Ecuador. Fuente: Desconocida

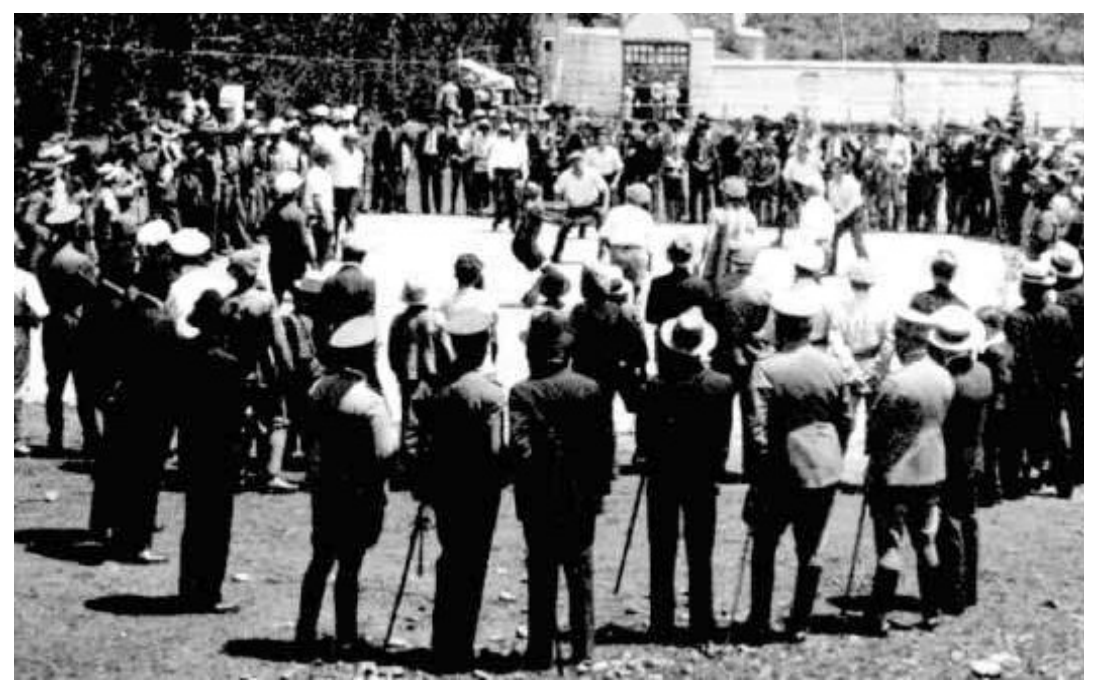

La Figura 11 también fue realizada en Quito, final del campeonato interprovincial de ecuavóley, realizada en las canchas del Colegio Mejía, observándose nuevamente los centenares de espectadores, la característica de las redes actuales con figuras de rombos y un balón de fútbol muy desgastado debido a la superficie de la cancha "cemento". 
Figura 11. Final campeonato de ecuavóley, 1952. Fuente: Luis Pacheco

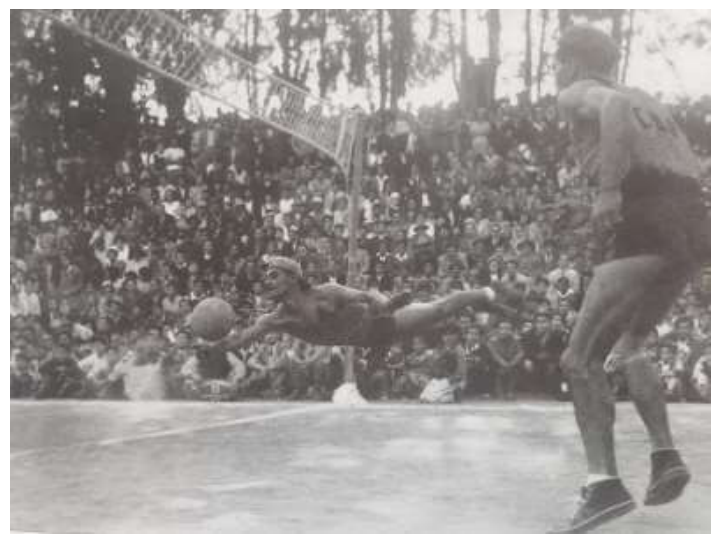

El siguiente recorte de periódico fue registrado en el cantón Cayambe, provincia de Pichincha se desconoce la fecha exacta en la que fue realizada la fotografía.

Figura 12. Final campeonato de ecuavóley, s/f. Fuente: Desconocida

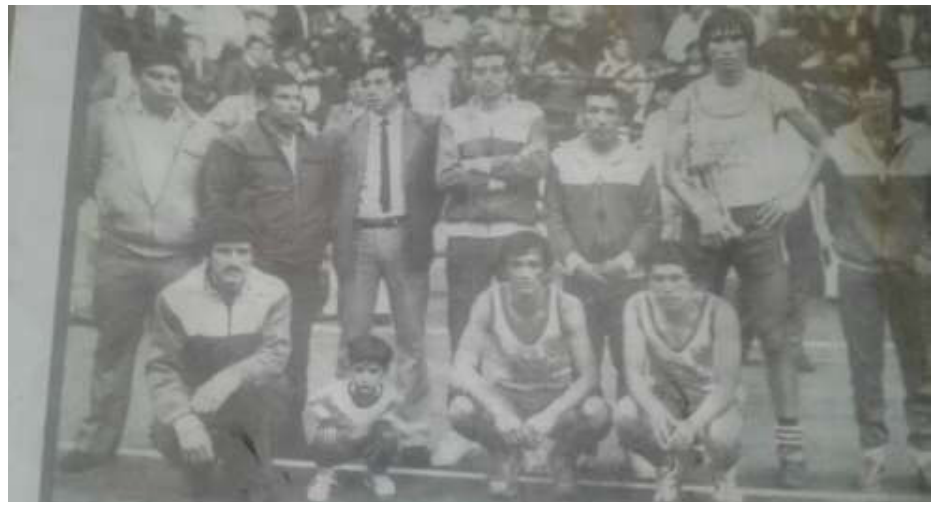

En la provincia de Imbabura, específicamente en el cantón Otavalo el ecuavóley era popular desde 1950, en la Figura 13 se observa un equipo totalmente uniformado y con una bandera, en el evento de inauguración.

Figura 13. Inauguración campeonato de ecuavóley. Fuente: Daniel Chávez

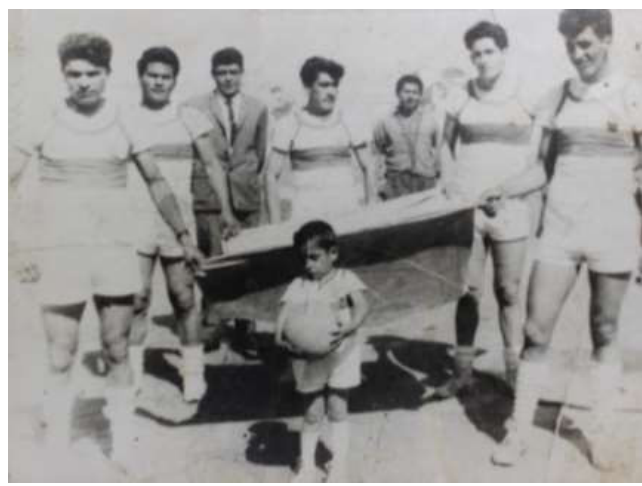


Mientras que en la Figura 13 y 14 se muestran fotografías de la inauguración del campeonato de ecuavóley realizado en la "Sociedad Artística", provincia de Imbabura, cantón Otavalo.

Figura 14. Inauguración ecuavóley, 1970. Fuente: Daniel Chávez

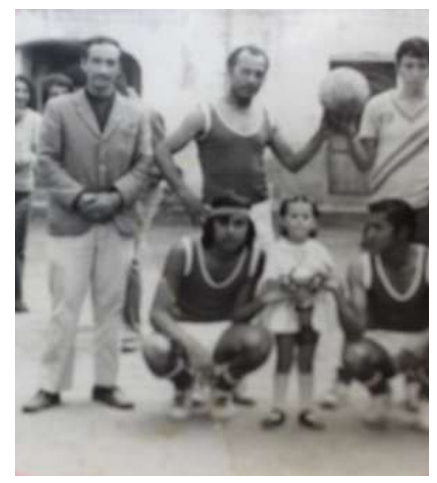

\section{DISCUSIÓN}

Una vez realizado el análisis histórico documental se puede afirmar que, en la provincia de Imbabura se jugaba ecuavóley a inicios de 1900 entre mestizos e indígenas, posteriormente en la provincia de Loja en el año de 1930, se jugaban partidos de exhibición en fiestas, de un híbrido de voleibol y ecuavóley con 5 jugadores, evidenciándose la afluencia masiva de personas, siendo los archivos fotográficos más antiguos, encontrados hasta el momento. Dando como resultado que estas dos provincias iniciaron con la práctica del ecuavóley.

Los primeros campeonatos de ecuavóley registrados fueron realizados en 1950 en Quito y Otavalo, siendo los primeros cantones del Ecuador en formar equipos, con la finalidad de disputar una copa, y haciendo competitivo al ecuavóley.

Después de hacer un análisis de datos en el programa estadístico cualitativo ATLAS.ti. se evidencia que el término "ecuavóley" fue utilizado a partir de 1950 contrastando con la fecha en la que fue patentado el término, de la misma manera desconociendo el creador real del término.

El ecuavóley va ligado a la cultura ecuatoriana, es por ello la gran cantidad de aficionados que se daban cita en cada una de las canchas desde los primeros partidos de exhibición hasta los campeonatos nacionales organizados en la actualidad.

Realizado esta investigación se pudo definir en qué provincias se originó el ecuavóley, su impacto social y cultural, brindando aspectos importantes al currículo de Educación Física, ya que en la actualidad al no existir estudios científicos que mencionen la historia del ecuavóley, 
un gran porcentaje de docentes trabajaban el bloque deportes con balón de una forma práctica, incumpliendo con las disposiciones del Ministerio de Educación del ecuador, complementar los ejercicios prácticos con teoría, siendo un aporte fundamental para el paradigma educativo ecuatoriano, el cual menciona que las y los estudiantes tienen que obtener aprendizajes significativos para la vida.

A pesar que en la actualidad sólo existe una investigación sobre la historia del ecuavóley, publicada por (Galeano-Terán, 2020a; Galeano-Terán, 2020b), la importancia de este estudio radica en el aporte al paradigma educativo ecuatoriano, ya que el deporte tradicional debe ser tomado en cuenta como contenido dentro de la formación integral del alumnado de Básica y Bachillerato, y ser utilizado como instrumento educativo que contribuya al desarrollo integral del currículum, además de inculcar en el alumnado hábitos de práctica deportiva, numerosos estudios afirman que parte del alumnado de los centros educativos tienen como único contacto con el deporte, el realizado en las clases de Educación física (Robles y Robles 2020).

Coincidiendo con los objetivos de este trabajo, y aportando a las bases teóricas que puedan ser utilizadas en las clases de Educación Física (Robles, 2010), en su estudio sobre el deporte en la etapa de Secundaria, afirma que los profesores de educación física utilizan en la mayor medida los deportes tradicionales, de esta manera facilitando al alumnado experiencias realmente educativas y significativas, (Méndez-Giménez y Fernández-Río 2011).

En los últimos años Parra y Sancho (2008) apuntan que los llamados deportes tradicionales han pasado a ser poco motivantes, postulados que contrastan con la realidad del ecuavóley, ya que cada día existen mayor número de personas de todas las edades que lo practican a nivel nacional e internacional, estos aspectos fundamentales deben ser tomados en cuenta para potenciar su práctica en el currículo ecuatoriano, impartiendo el ecuavóley de una manera teóricapráctica, y no únicamente práctica. Según Lara y Cachón (2010), los deportes alternativos han sido muy usados en los últimos años; sin embargo, hay un sector dentro del profesorado que, ya sea por desconocimiento o por falta de documentación, no los usa asiduamente.

Actualmente en Ecuador no existe ningún documento o guía pedagógica o didáctica sobre ecuavóley, su práctica efectiva o su historia, el único documento encontrado es un libro elaborado por el ex Ministerio del Deporte del Ecuador, hoy secretaría del Deporte, en el que se encuentra datos erróneos sobre la historia del ecuavóley y sus principales gestores, inclusive mencionando la existencia de una "Federación Internacional de Ecuavóley" en Italia, pese a que en la actualidad no existen asociaciones o federaciones de este deporte reconocidas en Ecuador u otros países por la Secretaría del Deporte, u organismos internacionales. 
En cuanto a la historia del ecuavóley, el objetivo de este trabajo no es polemizar, sino brindar los resultados de un proceso de investigación ordenado y responsable validado por el método científico, la investigación cualitativa permite conocer la historia basada en hechos reales desde perspectivas vivenciales de personas elegidas adecuadamente por el investigador con el objetivo de dar a conocer la realidad de los hechos, siendo interpretados adecuadamente en base a la información recolectada (Monly, 1980; Aróstegui, 1995; Duverger, 1996; Guba, 1989; Cabrera, 2005).

\section{CONCLUSIONES}

La presente investigación aporta elocuentemente con el currículo de Educación Física aprobado el 9 de marzo del 2016, ya que posibilita cumplir con los criterios de organización y secuencia de los contenidos, relacionando los conocimientos prácticos con los teóricos, incluyendo aprendizajes históricos y sociales aportando significativamente con la cultura, aspectos que vuelven significativo al aprendizaje. Particularmente este artículo científico aporta con dos de los cinco bloques curriculares del área de Educación Física "prácticas lúdicas” y "prácticas deportivas".

El análisis documental y fotográfico permitió recabar información valiosa sobre la génesis del deporte tradicional "ecuavóley", documentos que fueron complementados con entrevistas a profundidad realizadas a personas clave que tenían conocimiento de saberes transmitidos por sus antecesores, indagaciones valiosas que permitieron dar respuesta a los objetivos de investigación.

Este artículo científico es un aporte a la educación y a la población ecuatoriana en general ya que permitió conocer aspectos desconocidos del pasado con el objetivo de entenderlos y proyectarlos en futuros estudios sobre el ecuavóley y sus orígenes, deporte emblemático que cada día es más practicado dentro y fuera del Ecuador.

Después de un riguroso estudio descriptivo, se puede concluir que el deporte ecuatoriano "ecuavóley" se originó a partir de 1900, en Imbabura, a partir de 1930 hay registros de su práctica en Loja y los primeros campeonatos se realizaron en la década de 1950 en Quito y Otavalo, siendo las primeras ciudades en practicar el ecuavóley.

Posterior al análisis bibliográfico, se pudo evidenciar que Ecuador es el único país en el mundo que creó y desarrolló un deporte con pelota, "red" o net y jugado con la mano siendo 
similar únicamente el voleibol creado en Estados Unidos, teniendo características del campo de juego rectangular de la pelota maya, así como también de juegos y deportes tradicionales con pelota de origen europeo y asiático.

De esta manera estableciendo una teoría fundamentada sobre los inicios del ecuavóley, aportando significativamente al currículo de Educación Física ecuatoriano, brindando un aporte educativo y cultural a futuras generaciones a través de la historia del ecuavóley la sociedad demanda al sistema educativo una calidad de la enseñanza que hace actualizar la metodología, los recursos didácticos, la formación continua y los nuevos contenidos, proponiendo nuevas alternativas en el área correspondiente Ruiz (1996).

Finalmente se pudo conocer que a partir de 1950 se comenzó a usar el término "ecuavóley", resultados arrojados por el análisis de las entrevistas realizado por el programa estadístico ATLAS.ti, permitiendo conocer la verdad de los hechos, contradiciendo con la fecha en que fue patentado el término "ecuavóley", en este sentido se vuelve imprescindible mantener la etimología de la palabra ecuavóley, sin aumentar o disminuir letras ya que el término fue creado en Ecuador mostrando riqueza e importancia cultural.

\section{REFERENCIAS BIBLIOGRÁFICAS}

Acuerdo ministerial (0041-14/2016) de 09 de marzo, por el que se establece el Currículo Educación Física Ecuador para Educación General Básica y Bachillerato. Boletín oficial 2016-00020-A. http://educacion.gob.ec/educacion-educacion-fisica/

Aróstegui, J. (1995). La investigación histórica: teoría y método. Historia Contemporánea. España. https://scholar.google.com

Atkinson, P., Coffey, A., y Delamont, S. (1999). Ethnography: Post, Past, and Present. Journal of Contemporary Ethnography, 28(5), 460-471. https://doi.org/10.1177/089124199028005004

Bisquerra, R., y Alzina, R. B. (2016). Metodología de la investigación educativa. Editorial La Muralla. España

Blanco, R. (2016). Actividad física y deporte a lo largo de la historia: orígenes, motivación, causas, motivaciones y relación con el ámbito educativo. (Tesis de grado) Universidad de la Rioja España http://www.unirioja.es

Bringas, M. (2002). Una aportación a la evolución de la pelota vasca en el ámbito de la estrategia, táctica y técnica: mano individual, en trinquete vs. En frontón de pared izquierda. (Tesis Doctoral). Universidad del País Vasco, España. http://dialnet.unirioja.es/servlet/tesis?codigo=212479 
Burgués, P. L. (2000). Juegos y deportes populares tradicionales (Vol. 567). Publicaciones Inde.

Cabrera, F. C. (2005). Categorización y triangulación como procesos de validación del conocimiento en investigación cualitativa. Theoria, 14(1), 61-71. http://www.redalyc.org/pdf/299/29900107.pdf

Cifuentes, J. F., y Ramírez, S. P. (2019). Los ancestrales deportes de pelota maya en el contexto educativo de Guatemala. Revista Latinoamericana de Educación y Estudios Interculturales 3(4). España.

Gialdino, V. (2006). Estrategias de investigación cualitativa. Editorial Gedisa. España

Del Valle Gastaminza, F. (1999). El análisis documental de la fotografía. Cuadernos de documentación multimedia, Revista Espacios, (8), 26. http://www.revistaespacios.com/cited2017/cited2017-17. $\underline{\text { html }}$

Deslauriers, J. P. (2004). Investigación cualitativa: guía práctica. Editorial Papiro.

Diem, C. (1966). Historia de los deportes. Editorial Caralt. España. http://museodeljuego.org/wpcontent/ uploads/contenidos_0000000438 docu1.pdf

Dulzaides Iglesias, M. E. y Molina Gómez, A. M. (2004). Análisis documentaly de información: dos componentes de un mismo proceso. Acimed, 12(2), 1-1. http://scielo.sld.cu/scielo.php?scripci_arttext\&pid=S1024-94352004000200011

Duverger, M. (1996.). Métodos de las ciencias sociales/por Maurice Duverger Gijón: Trea. España.

Esparza, D. (2019). Historia y deporte: la necesidad de investigar génesis de deportes concretos. Revista Internacional de Ciencias del Deporte. 15(56), 119-122. http://doi.org/10.5232/ricyde2019.056ed

Galeano, M. E. (2003). Diseño de proyectos en la investigación cualitativa. Editorial Universitaria. España

Galeano-Terán, A. (2020a). Ecuavóley origen e historia en la provincia de Imbabura. Recinatur International fournal of Applied Sciences, Nature and Tourism, 2(1), 81-97. http://revistasojs.utn.edu.ec/ index.php/recinatur/article/view/410/313

Galeano-Terán, A. (2020b). Historia del ecuavóley: evolución cultural. Horizontes. Revista De Investigación En Ciencias De La Educación, 4(15), 309 - 325. https://doi.org/10.33996/revistahorizontes. v4i15.118

Galeano-Terán, A., y Chuquín, P. (2020). Ecuavóley, el rey de los deportes para los ecuatorianos en el mundo. Horizontes Revista de Investigación en Ciencias de la Educación, 4(16), 398-414. http:// doi.org/10.33996/revistahorizontes.v4i16.104

Galeano-Terán, A. S. (2018). Diseño instruccional de actividades deportivas complementarias en el currículo de educación física para la formación integral del estudiante (Tesis de Maestría). Universidad Técnica del Norte. Ecuador. http://repositorio.utn.edu.ec/handle/123456789/7827 
Gil, J., Rodríguez, G., y García, E. (1999). Metodología de la investigación cualitativa. Málaga: aljibe. España http://catedranaranja.com.ar/taller5/notas_T5/metodologia_investig_cap.3.pdf

Gorris, J.M. (1981). El juego y el juguete. Queimada, España.

Guba, E. G. (1989). Criterios de credibilidad en la investigación naturalista. La enseñanza: su teoría y su práctica. Akal.148-165. https://dialnet.unirioja.es/servlet/articulo?codigo=6220913

Jiménez, E. (2019). Retrospectiva histórica del juego y deporte tradicional a través de la cultura segoviana. Historia de la Educación, 38, 127-154. http//dx.doi.org/10.14201/hedu201938127154

Lara, A. J., y Cachón, J. (2010). Kinball: los deportes alternativos en la formación del/la docente de educación física. Congrés Internacional de Ditáctiques, España http://dugidoc.udg.edu/bitstream/ handle/10256/3001/491.pdf?sequence=1

Lavega, B. (2000). Juegos y deportes populares y tradicionales. INDE Editorial, España.

López, A. J. M. (2012). Introducción a la historia de los deportes en la China Antigua= Introduction to the history of sports in the Ancient China. Materiales para la Historia de lDeporte, (10),105-116. http://dialnet.unirioja.es/servlet/articulo?codigo $=4094564$

Martínez Benítez, J. E. (2018). Diferenciales de Género y Actividad Física en los estudiantes de la Universidad Central del Ecuador. (Tesis doctoral). Universidad de Alicante. España http://hdl.handle. net/10045/999

Marzal, J. M. (2007). Cómo se lee una fotografía: interpretaciones de la mirada. Ediciones Cátedra, España.

Méndez-Giménez, A., y Fernández-Río, J. (2011). Análisis y modificación de los juegos y deportes tradicionales para su adecuada aplicación en el ámbito educativo. Retos. Nuevas tendencias en Educación Física, Deporte y Recreación, (19),54-58. http://www.redalyc.org/pdf/3457/345732285011.pdf

Parra, C., y Sancho, M. (2008). Deportes alternativos: una propuesta práctica desde el punto de vista del profesor. In V congreso nacional y III congreso iberoamericano de deporte en edad escolar: "Nuevas Tendencias y perspectivas de futuro, España, 351-374.

Paz, M. (2003). Investigación cualitativa en educación. Fundamentos y tradiciones. Editorial Mcgraw Hill. México.

Peña Vera, T., y Pirela Morillo, J. (2007). La complejidad del análisis documental. Información, cultura y sociedad. Revista del Instituto de Investigaciones (16), 55-81. http://eprints.rclis.org/17138/

Pulido-Cortés, Ó. (2017). ¿Sirve la historia de la educación hoy?. Praxis \& Saber, 8(17), 9- 14.http:// www.scielo.org.co/scielo.php?script=sci_arttext\&pid=S2216- 01592017000200009\#B2 
Revilla, F. (2000). ¿Resolución de un problema? El juego de pelota mesoamericano. Goya: Revista de arte, (277), 258-266. http://dialnet.unirioja.es/servlet/articulo?codigo $=8358$

Robles, J. (2010). Motivos que llevan a los profesores de Educación Física a elegir los contenidos deportivos en la E.S.O. Retos. Nuevas tendencias en Educación Física, Deporte y Recreación, 18, 5-8.

Robles, A., y Robles, J. (2020). La participación en las clases de educación física la ESO y Bachillerato. Un estudio sobre un deporte tradicional (Balonmano) y un deporte alternativo Retos, (39), 7883. http://doi.org/10.47197/retos.v0i39.78129

Ruíz, J. G. (1996). Juegos y deportes alternativos en la programación de Educación física escolar. Editorial Deportiva Agonos. España.

Ruíz, J. J. (2015). Las entrevistas en profundidad y la biografía. Revista San Gregorio, 48- 55. http://www. revista.sangregorio.edu.ec/index.php/REVISTASANGREGORIO/article/ view/115

Sainz, M. (1992). Historia de la educación física. Editorial Donostia. 27-47. http://d1wqtxts1xzle7. cloudfront.net

Salinero, J. G. (2004). Estudios descriptivos. Nure investigación. 1-3. http://webpersonal.uma.es/de/jmpaez/websci/BLOQUEIII/DocbIII/Estudios\%20descriptivos.pdf

Sánchez, J. M. (2006). El documento fotográfico. Historia, usos, aplicaciones. Gijón: Trea, 404.

Sánchez, R. (2020). Antropología del deporte: lineamientos teóricos. Editorial: Consejo Superior de Investigaciones Científicas, España.

Schwandt, T. A., Denzin, N. K., y Lincoln, Y. S. (1994). Handbook of qualitative research.Ed: Denzin y Lincoln. Inglaterra

Torrebadella-Flix, X. (2019). Los orígenes del voleibol en España en el contexto escolar, militar y civil (1920-1938). RICYDE. Revista Internacional de Ciencias del Deporte, 15(56), 187-208. http://www. cafyd.com/REVISTA/05605.pdf

Torregrosa, J. F. (2010). Modelos para el análisis documental de la fotografía. Documentación de las Ciencias de la Información, 33, 329-342. https://scholar.google.com/scholar

Viñao Frago, A. (2016). La Historia de la Educación como disciplina y campo de investigación: viejas y nuevas cuestiones. Espacio, Tiempo y Educación, 3(1), 21- 42. doi: http://dx.doi.org/10.14516/ ete.2016.003.00L3

Vilches, L. (1993). La lectura de la imagen. Prensa, cine, televisión. Paidós. España 